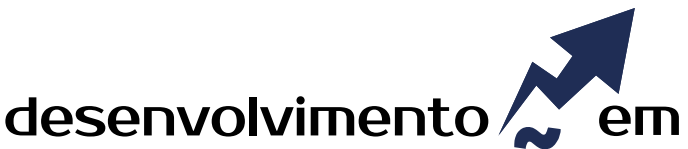 QUESTÃO
}

\section{Diversificação da Produção com Flores Tropicais Qual o Interesse dos Agricultores Familiares de Tangará da Serra-MT?}

http://dx.doi.org/10.21527/2237-6453.2020.50.129-145

Recebido em: 30/11/2017

Aceito em: 5/8/2019

\section{Josiane Silva Costa dos Santos ${ }^{1}$, Cleci Grzebieluckas², Raimundo Nonato Cunha de França ${ }^{3}$, Francisco Xavier Freire Rodrigues ${ }^{4}$, Edineia Souza Nunes ${ }^{5}$}

\begin{abstract}
RESUMO
O objetivo do estudo foi identificar o interesse dos agricultores familiares na diversificação das atividades agrícolas com o cultivo de flores tropicais no município de Tangará da Serra-MT. Trata-se de uma pesquisa de natureza descritiva com abordagem quali-quantitativa. A amostra consistiu em 19 casais de agricultores. $O$ instrumento de coleta de dados foi um formulário semiestruturado, contendo perguntas abertas e fechadas. A aplicação da pesquisa ocorreu por meio de visitas in loco realizadas nas propriedades rurais do município. Constatou-se que $94,74 \%$ das famílias conhecem as flores tropicais, entretanto somente conseguiram identificar por fotos ou uso do nome popular, e que 73,68\% já visualizaram espécies nativas na propriedade. Apesar de 52,63\% demonstrarem interesse no cultivo de flores tropicais como estratégia de diversificação de renda, também apresentaram muitas dúvidas em relação às formas de cultivo, investimento e comercialização, por se tratar de uma atividade pouco explorada no Estado. Nesse sentido, a floricultura tropical carece de parcerias público-privadas para subsidiar o agricultor com assistência técnica especializada, linhas de crédito específicas e estruturação de canais de comercialização para escoamento da produção no contexto social da região.
\end{abstract}

Palavras-chave: Agricultura familiar. Floricultura tropical. Alternativa de renda.

DIVERSIFICATION OF PRODUCTION WITH TROPICAL FLOWERS:

WHAT THE INTEREST OF FAMILY FARMERS OF TANGARÁ DA SERRA-MT

\begin{abstract}
The objective of the study was to identify the interest of family farmers in the diversification of agricultural activities with the cultivation of tropical flowers in the municipality of Tangará da Serra, MT. It is a research of descriptive nature with a qualitative-quantitative approach. The sample consisted of 19 pairs of farmers. The data collection instrument was a semi-structured form, containing open and closed questions. The research was carried out through on-site visits to the rural properties of the municipality. It was verified that $94.74 \%$ of the families know the tropical flowers, however, they can only identify by photos or use of the popular name and that $73.68 \%$ have already visualized native species in the property. Although $52.63 \%$ showed an interest in the cultivation of tropical flowers, as a strategy of income diversification, they also presented many doubts regarding the forms of cultivation, investment and commercialization, since this is an activity that is not widely explored in the state. In this sense, the tropical floriculture needs public-private partnerships to subsidize the farmer with specialized technical assistance, specific credit lines and structuring of commercialization channels to flow production in the social context of the region.
\end{abstract}

Keyword: Family farming. Tropical floriculture. Income alternative.

\footnotetext{
${ }^{1}$ Mestre em Ambiente e Sistemas de Produção Agrícola pela Universidade do Estado de Mato Grosso (Unemat). Professora da Universidade do Estado de Mato Grosso (Unemat). josyane.costa@hotmail.com

2 Doutora em Engenharia de Produção pela Universidade Federal de Santa Catarina (UFSC). Professora da Universidade do Estado de Mato Grosso (Unemat). cleci@unemat.br

${ }^{3}$ Doutor em Ciências Sociais pela Universidade Federal do Rio Grande do Norte (UFRN). Professor da Universidade do Estado de Mato Grosso (Unemat).raimundofranca@unemat.br

${ }^{4}$ Doutor em Sociologia pela Universidade Federal do Rio Grande do Sul (UFRGS). Professor da Universidade do Estado de Mato Grosso (Unemat). fxsociologo@yahoo.com.br

${ }^{5}$ Mestre em Ambiente e Sistemas de Produção Agrícola pela Universidade do Estado de Mato Grosso (Unemat). Professora da Universidade do Estado de Mato Grosso (Unemat).edineiaqueroz@hotmail.com
} 
A agricultura familiar destaca-se por sua dinâmica de produção e comercialização, assumindo papel fundamental no cenário econômico. São cerca de 4,4 milhões de famílias agricultoras, as quais representam $84 \%$ dos estabelecimentos rurais brasileiros, contribuindo na geração de renda, permanência das famílias no campo, controle da inflação por meio da maior oferta de produtos e sustentabilidade das atividades agrícolas (MDA, 2017). O setor influencia e é influenciado tanto no ambiente interno quando externo; assim, faz-se necessário buscar novas alternativas, criando estratégias de diversificação em áreas ainda pouco exploradas (STUANI; NECKEL; FICAGNA, 2016), por exemplo, a floricultura tropical.

O Brasil é considerado um país privilegiado em razão da ampla biodiversidade e das características edafoclimáticas, possibilitando diferentes alternativas de cultivo de flores (LANGE; AREND, 2012). Poucos são, todavia, os polos de produção que sustentam o fluxo de abastecimento das amplas faixas territoriais do país; além disso, as flores e plantas regionais acabaram perdendo o valor e preferência ante a qualidade, padrão e ofertas regulares originadas de floriculturas mais tecnificadas e competitivas (JUNQUEIRA; PEETZ, 2008).

Apesar de a floricultura ser considerada supérflua e restrita a uma pequena parte da sociedade de alta renda, o setor tem exercido importantes papéis sociais, culturais e ecológicos, além do econômico. Social - por estar relacionado ao uso de pequenas propriedades rurais, colaborar para a diminuição do êxodo rural, permitir que a atividade seja familiar e empregar pessoas de ambos os sexos e diferentes idades; cultural - por envolver diversas cerimônias, como casamentos, formaturas, funerais, eventos e o uso em datas importantes do ano, como dia das mães, finados, namorados, etc.; e ecológico - por contribuir na preservação de espécies nativas (TERRA; ZUGE, 2013). Econômico com capacidade de gerar de 50 mil a 100 mil reais por hectare/ano (DUVAL, 2014).

Sendo assim, a floricultura tropical surge como alternativa para agricultores familiares de Mato Grosso, experiência já vivenciada por produtores no Estado como possibilidade de emprego e renda (SANTOS, 2015; PERSONA, 2016). Embora o Estado seja considerado o maior produtor de cereais, leguminosas e oleaginosas (representados por soja, milho e arroz - 93,5\%) (IBGE, 2017), também possui condições de clima e solo para o cultivo de flores tropicais (LAMAS, 2004). Diante do exposto, o objetivo desta pesquisa foi identificar o interesse dos agricultores familiares na diversificação das atividades agrícolas com o cultivo de flores tropicais no município de Tangará da Serra-MT.

O crescimento populacional, habitacional, de instituições de Ensino Superior e de clínicas no município, tem sido intenso nos últimos anos, caracterizando-o como uma região polo. Esta evolução possibilita oportunidades e a necessidade de oferta de vários serviços de decoração, como assinatura floral, decorações de eventos e paisagismo, podendo ser também uma alternativa para o fortalecimento da agricultura familiar. Justifica-se o estudo tendo em vista que Mato Grosso possui um abastecimento de flores deficitário, fornecido, em sua maioria, pelo Estado de São Paulo (NASCIMENTO, 2014). Torna-se necessário, portanto, que pesquisas sejam realizadas visando a conhecer os interesses dos agricultores em desenvolver uma nova estratégia de ganho econômico, e também pelo fato de estudos dessa natureza serem incipientes. 


\section{REFERENCIAL TEÓRICO}

\section{Agricultura Familiar}

Com o advento da tecnologia e modernização da agricultura, o processo de produção aumentou, originando divisas econômicas a partir da exportação. Tal transformação contribuiu para que pequenos agricultores não conseguissem se adequar ao modelo capitalista de produção, gerando precarização do acesso aos meios de trabalho, ausência de tecnologias, limitação da mobilidade social e pobreza. Tais mudanças contribuíram de forma negativa para a organização do trabalho familiar rural, provocando o aumento do êxodo rural (SILVA; JESUS, 2010).

Na década de 50 do século 20, iniciou-se a discussão sobre a necessidade da reforma agrária e seu modelo, mobilizando um conjunto de forças sociais que acirrou um confronto de interesses (GEHLEN, 2004). A partir de então surgiram diversas lutas de movimentos que batalharam por créditos, melhorias de preços, regulamentação da previdência social rural, formas diferenciadas de comercialização, etc. (SCHNEIDER, 2010).

Essas lutas deram visibilidade à questão agrária brasileira, produtora de diferenças sociais tão ou mais expressivas quanto às da sociedade em geral. Tal visibilidade provocou mudanças no modelo agrário, priorizando o social, tanto simbólico quanto político. Embora o governo hesitasse em relação à reforma agrária, assumiu que sua efetivação reproduziria um modelo de agricultura familiar, o que teve início em 1990 (GEHLEN, 2004).

A consolidação da agricultura familiar ocorreu com a criação do Programa Nacional de Fortalecimento da Agricultura Familiar (Pronaf), por meio do decreto 1.946 de 1996 e, posteriormente, com a Lei da Agricultura Familiar, Lei no 11.326/2006 (SCHNEIDER, 2010). Esta lei considera agricultor familiar aquele que desenvolve atividades econômicas no meio rural atendendo alguns requisitos básicos: não deter propriedade rural maior do que quatro módulos fiscais; utilizar exclusivamente mão de obra familiar nas atividades econômicas da propriedade; possuir maior parte da renda familiar proveniente das atividades agropecuárias desenvolvidas no estabelecimento rural (BRASIL, 2006).

A agricultura familiar assume um papel importante para a economia e o desenvolvimento social, por se tratar da forma predominante de produção de alimentos no mundo. Contribui para a geração de renda e sustentabilidade das atividades agrícolas mediante o desenvolvimento simultâneo de duas ou mais atividades, uma vez que $9 \mathrm{em}$ cada 10 das 570 milhões de propriedades agrícolas no mundo são conduzidas por famílias (FAO..., 2014). Um exemplo desse contexto é a floricultura, que tem se concentrado em pequenas e médias propriedades rurais, utilizada como alternativa de diversificação de renda para agricultores familiares (DUVAL, 2014).

\section{Diversidade e estratégias de diversificação}

A diversidade é entendida como meios e modos pelos quais os indivíduos lidam com as adversidades e os condicionantes nos contextos em que vivem. A diversificação consiste em fortalecer o meio de vida no contexto rural. É uma maneira de criar 
mecanismos das opções e estratégias de trabalho e renda, quanto mais diversificada a unidade produtiva, maiores serão as chances e oportunidades para fazer escolhas (SCHNEIDER, 2010).

A diversificação agrícola consiste na produção de duas ou mais atividades em uma propriedade rural; por exemplo, o cultivo de café, milho, leite e criação de frangos, classificando a unidade de produção como diversificada (SIMÃO, 2005). Apenas diversificar, contudo, pode trazer poucas melhorias para a família. Em alguns casos torna-se necessário o desenvolvimento simultâneo da diversificação rural, prática conjunta de atividades agrícolas primárias (produção) e não agrícolas (industrialização e prestação de serviços), envolvendo atividades do setor secundário e terciário (SILVA, 2001).

Os motivos que levam à diversificação rural são muitos e podem estar associados a vários fatores, como: edafoclimáticos ou socioeconômicos, apresentando-se por meio da sazonalidade, dos riscos (clima, pragas, doenças), vulnerabilidade, migrações, efeitos de mercado de trabalho (preço e demanda), baixa disponibilidade de recursos financeiros, entre outros. Diante destas adversidades, é perceptível a importância de o agricultor criar estratégias de diversificação da produção a fim de superar e adaptar-se há situações instáveis (BEZERRA; SCHILINDWEIN, 2017).

A diversificação colabora de forma determinante no desenvolvimento rural e contribui na distribuição e diversificação das fontes de renda, resultando na superação da pobreza; amplia a produtividade rural e diversificação no interior da unidade de produção e a inserção de rendas não agrícolas, auxiliando na capacidade de custeio; reduz o uso intensivo do solo e resulta na intervenção das relações de gênero, podendo alterar as relações de dominação; provoca maior segurança em relação aos efeitos macroeconômicos e menor dependência do mercado e das oscilações constantes de preços (SCHNEIDER, 2010).

O Quadro 1 apresenta como podem ocorrer as estratégias de diversificação no contexto rural.

\section{Quadro 1 - Estratégias de reprodução dos agricultores}

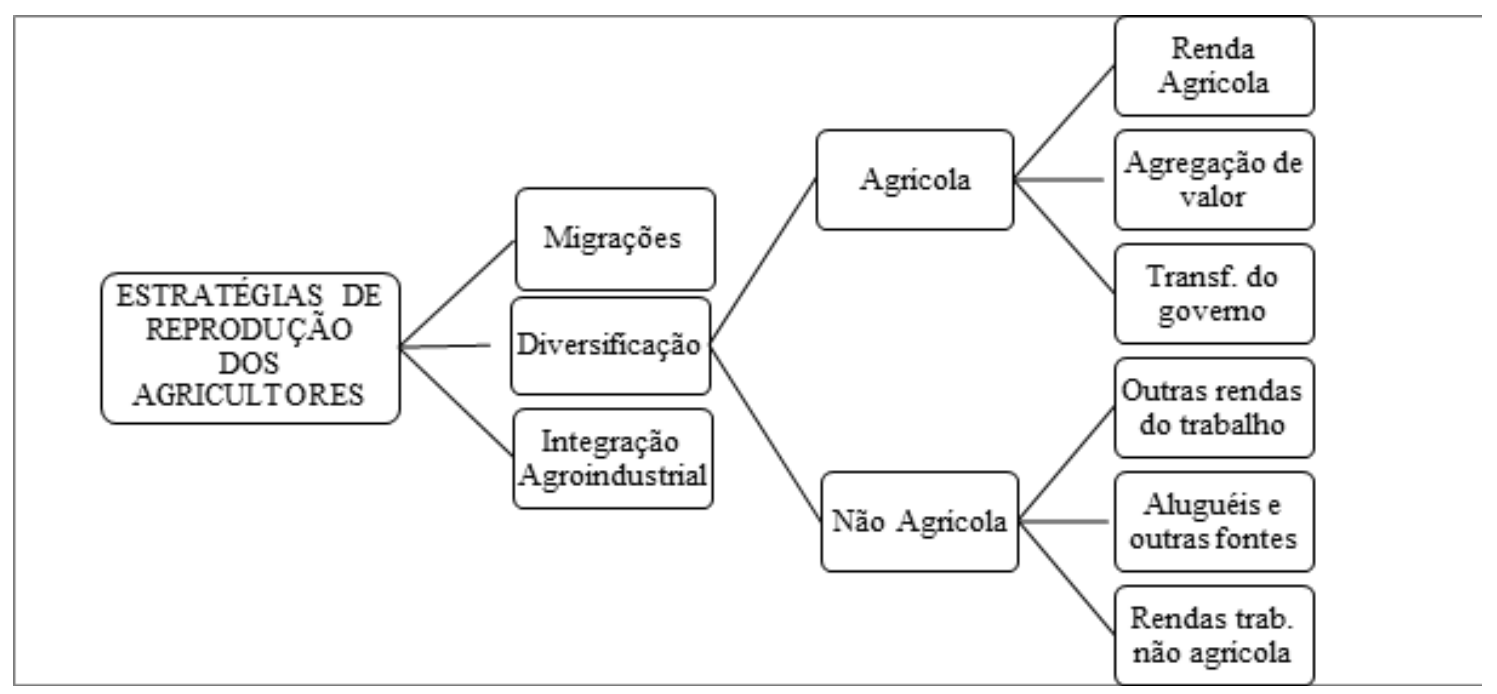

Fonte: Adaptado de Schneider (2010).

O Quadro 1 destaca a importância que a diversificação rural representa para a agricultura, possibilitando diferentes alternativas de geração de renda e oportunizando condições de cidadania no meio rural, afastando a possibilidade do êxodo. 


\section{Caracterização da Floricultura Tropical}

As flores tropicais possuem características peculiares em relação às demais, como rusticidade, perenidade, diversidade de cores, portes e formas exóticas. Algumas espécies produzem o ano todo, e se adaptam em regiões com altas temperaturas e disponibilidade de água (LAMAS, 2004; LOGES et al., 2005). O cultivo não é tão exigente se comparado às demais flores (UNEMOTO, 2010), o que contribui para o aumento da demanda e conquista de espaço no mercado, principalmente como flor de corte, em virtude da maior durabilidade pós-colheita (LOGES et al., 2005).

Os países desenvolvidos apresentam limitações no cultivo de flores tropicais por terem condições climáticas desfavoráveis e necessitarem de investimentos em altas tecnologias, onerando o custo final do produto (LOGES et al., 2005; LOMACHINSKY, 2005); fato que tem incentivado a produção em países tropicais, como o Brasil, que dispõe de terra, água, clima, energia e mão de obra, elementos que influenciam na qualidade do produto e possibilitam menores custos e preços mais competitivos (LOGES et al., 2005).

No Brasil, a floricultura tropical obteve reconhecimento em meados da década de 30 do século 20 a partir do trabalho pioneiro do paisagista Roberto Burle Marx, com a valorização de espécies nativas ou exóticas, reforçando os valores nacionais (LOMACHINSKY, 2005), todavia a produção comercial teve início na década de 90 (AKI; PEROSA, 2002). O Nordeste é o principal produtor da floricultura tropical, com destaque nos Estados de Alagoas, Pernambuco e Ceará, favorecendo muitas famílias de agricultores na geração de emprego e renda, além de promover o desenvolvimento econômico e social da região. Outros Estados, como Mato Grosso, Mato Grosso do Sul, Pará e Minas Gerais, também têm cultivado flores tropicais (ALMEIDA et al., 2012).

\section{PROCEDIMENTOS METODOLÓGICOS}

\section{Área de Estudo}

A pesquisa foi realizada no município de Tangará da Serra-MT, situado na região Sudoeste, a $240 \mathrm{~km}$ da capital Cuiabá-MT, localizado entre as coordenadas geográficas Latitude Sul 14ㅇ 04' 38" e Longitude Oeste 570 03' 45" Oeste (SEPLAN, 2015). Em 2010 o Índice de Desenvolvimento Humano Municipal (IDH) era de 0,729 (ATLAS..., 2013). Em 2018 foi considerado o quinto município mais populoso, com população estimada de 101.764 (IBGE, 2018).

Possui uma área total de $11.423,04 \mathrm{~km}^{2}$, e aproximadamente $51 \%$ é indígena do povo Paresí, primeiros habitantes dos campos do Tapirapuã, local onde está edificada a zona urbana e rural de Tangará da Serra. Nas décadas de 60 e 70 houve um significativo fluxo migratório de famílias oriundas dos Estados de Minas Gerais, São Paulo, Paraná e de alguns Estados do Nordeste. Esse fluxo ocorreu em virtude da propaganda da fertilidade do solo para o plantio de café (OLIVEIRA, 2003).

Até a década de 70 Tangará da Serra-MT era distrito do município de Barra do Bugres-MT, distante $80 \mathrm{~km}$, e em 13 de maio de 1976 tornou-se município. A partir de 1980 ocorreu o segundo fluxo migratório da Região Sul, motivado pela produção em 
larga escala com uso de tecnologias mecanizadas para o plantio de monoculturas, como soja e milho (OLIVEIRA, 2009). Tais características históricas e culturais de diversidade vêm contribuindo para a evolução e crescimento do município.

Possui uma economia estratificada em indústria, comércio e serviços, e este último abrange $56,6 \%$. As culturas de soja e cana-de-açúcar são atividades predominantes na região (SETUR, 2015). A feira do produtor no município possui cerca de 318 feirantes, principalmente da agricultura familiar (SCHWAAB, 2017), e conta com uma variedade de produtos in natura, processados, fitoterápicos e de flores e plantas paisagísticas (FARIA et al., 2016).

\section{Caracterização da Pesquisa}

A pesquisa caracteriza-se quanto ao tipo como descritiva, com abordagem quali-quantitativa. As pesquisas descritivas buscam investigar, analisar, registrar e classificar os fatos ou fenômenos sem a interferência do pesquisador (RICHARDSON et al., 2012), enquanto as pesquisas qualitativas visam a coletar informações das opiniões, costumes, hábitos e anseios dos entrevistados (MALHOTRA et al., 2005). Já as quantitativas procuram a quantificação dos resultados produzindo percentuais e valores monetários (RICHARDSON et al., 2012). A fim de interpretar o material qualitativo, utilizou-se a análise de conteúdo, que objetiva a compreensão e descrição da construção de conhecimento acerca do objeto estudado (CAREGNATO; MUTTI, 2006).

Tendo em vista a necessidade de água na produção de flores tropicais (LAMAS, 2004), utilizou-se como critérios de seleção dos pesquisados a disponibilidade de recurso hídrico na propriedade, estar localizado próximo ao perímetro urbano e receber assistência técnica da Empresa Matogrossense de Pesquisa, Assistência e Extensão Rural (Empaer). Com a finalidade de identificar tais características, buscou-se informações junto a Empaer, a qual disponibilizou os dados cadastrais (endereço, nome, telefone, etc.) de 21 agricultores com este perfil. Destes agricultores, dois não tiveram interesse em participar da pesquisa, resultando em uma amostra com 19 casais de agricultores familiares.

Os agricultores foram esclarecidos sobre a pesquisa e convidados a participar. Em concordância, foi solicitada a adesão ao Termo de Consentimento Livre e Esclarecido (TCLE), com garantia de anonimato destes, que autorizaram o registro de fotos do local e a divulgação dos dados fornecidos. A pesquisa foi submetida à análise pelo Comitê de Ética em Pesquisa (CEP) da Universidade do Estado de Mato Grosso (Unemat) e aprovada sob Parecer do CEP Unemat no 1.902.410/2017.

$O$ instrumento de coleta utilizado foi o formulário semiestruturado contendo perguntas abertas e fechadas. Antes da aplicação efetiva, realizou-se um pré-teste com uma agricultora do município que investiu na produção de flores tropicais, a fim de avaliar a exatidão e coerência das perguntas e respostas, conforme recomendado por Hair Junior et al. (2005). Após a revisão do formulário realizou-se a aplicação definitiva por meio de visitas in loco às propriedades. 


\section{RESULTADOS E DISCUSSÃO}

\section{Perfil Socioeconômico dos Agricultores}

Observa-se uma variação cultural entre os agricultores entrevistados, com predominância dos Estados do Paraná, São Paulo e Mato Grosso, contudo há uma diversidade de gêneros (Tabela 1).

Tabela 1 - Naturalidade dos agricultores entrevistados

\begin{tabular}{lcccc}
\hline \multirow{2}{*}{ Origem } & \multicolumn{2}{c}{ Homem } & \multicolumn{2}{c}{ Mulher } \\
\cline { 2 - 5 } & Quantidade & Percentual \% & Quantidade & Percentual \% \\
\hline Espírito Santo & - & - & 1 & 5,26 \\
Goiás & 1 & 5,26 & - & - \\
Mato Grosso & 2 & 10,53 & 3 & 15,79 \\
Mato Grosso do Sul & 1 & 5,26 & 1 & 5,26 \\
Minas Gerais & - & - & 3 & 15,79 \\
Pará & - & - & 1 & 5,26 \\
Paraná & 6 & 31,58 & 6 & 31,58 \\
Pernambuco & 1 & 5,26 & - & - \\
Rio Grande do Sul & 1 & 5,26 & 2 & 10,53 \\
Rondônia & 1 & 5,26 & - & - \\
São Paulo & 6 & 31,58 & 2 & 10,53 \\
\hline Total & $\mathbf{1 9}$ & 100,00 & $\mathbf{1 9}$ & 100,00 \\
\hline
\end{tabular}

Fonte: Dados da pesquisa (2017).

Essa variação cultural está ligada à identidade do agricultor, que, na visão de Gazolla e Schneider (2007), trazem consigo a herança do saber-fazer de cada região, o que se socializa de geração para geração ou até mesmo com vizinhos rurais, contribuindo para as várias formas de fazer agricultura. Em alguns casos esse processo migratório ocorreu em razão do êxodo rural, contribuindo com o desenvolvimento da agricultura na região Centro-Oeste (MORENO, 2005).

As famílias de agricultores encontram-se com idade superior a 46 anos, sendo $78,95 \%$ homens e $84,21 \%$ mulheres (Tabela 2). Situação semelhante foi identificada em outros municípios mato-grossenses, tais como Alta Floresta, Sorriso, Juína, Nova Xavantina, Nossa Senhora do Livramento e Aripuanã (HAUBRICHT; FIORINI, 2014; TUMELERO; MATTOS, 2006; CAVALHEIRO et al., 2014; MORAES; SANT'ANA, 2015; ARRUDA; VILANOVA; CHICHORRO, 2008; LIMA; ZOMER, 2011). A mesma característica também foi percebida por Godoy et al. (2010) em municípios do Rio Grande do Sul.

Tal realidade corrobora com Cintra e Bazotti (2012), os quais destacam que o processo migratório da faixa etária produtiva no campo vem crescendo em virtude dos encantamentos do meio urbano (tecnologia, comunicação, etc.), em que cada vez mais jovens vão para a cidade e quem fica na terra são os mais velhos, reduzindo, assim, a força de trabalho. 
Tabela 2 - Faixa etária dos agricultores

\begin{tabular}{lrrrr}
\hline \multirow{2}{*}{ Idade } & \multicolumn{2}{c}{ Homem } & \multicolumn{2}{c}{ Mulher } \\
\cline { 2 - 6 } & Quantidade & Percentual \% & Quantidade & Percentual \% \\
\hline 18 a 35 anos & 1 & 5,26 & 1 & 5,26 \\
36 a 45 anos & 3 & 15,79 & 2 & 10,53 \\
46 a 55 anos & 5 & 26,32 & 9 & 47,37 \\
Acima de 56 anos & 10 & 52,63 & 7 & 36,84 \\
\hline Total & $\mathbf{1 9}$ & 100,00 & $\mathbf{1 9}$ & 100,00 \\
\hline
\end{tabular}

Fonte: Dados da pesquisa (2017).

Outro fator é a composição das famílias que diminuiu, pois a maioria delas $(52,63 \%)$ têm entre três e quatro filhos. Essa realidade é confirmada por Berquo e Cavenaghi (2006), os quais destacaram que no Brasil rural, em 1991, a média de filhos era de 4,3 e, já no ano de 2004, essa média reduziu para 1,2 filhos. Além dessa redução, as famílias contam com a mão de obra de um filho ou nenhum (73,68\%). Um dos fatores que tem influenciado este resultado é a busca destes jovens por novas alternativas de renda no anseio por um futuro melhor em relação à vida no campo. Resultado semeIhante vem ocorrendo em algumas regiões do Sul do Brasil (SPANEVELLO et al., 2010).

Já na Região do Alto Uruguai, no Rio Grande do Sul, existem estratégias que têm contribuído para a continuidade dos jovens no campo, como remuneração pelo trabalho nas unidades familiares, diversificação da produção, atividades complementares à agricultura e políticas públicas que possibilitam o desenvolvimento rural e a continuidade da agricultura familiar (DEGGERONE, 2014), conforme apresentado por Schneider (2010) no Quadro 1.

A escolaridade das famílias tem melhorado, tendo em vista que não houve ocorrência de não alfabetizados entre os filhos, ao contrário dos pais, visto que a maioria possui o ensino primário (Tabela 3). Essa mudança de cenário pode estar ligada ao fato de a região ser polo em educação superior, facilitando o acesso destas famílias e também a mudança no contexto cultural na forma de pensar e valorizar a educação por intermédio do incentivo aos filhos, diferentemente do que ocorria no passado, quando, segundo os entrevistados, os pais incentivavam ao trabalho na terra e não à educação.

As áreas do Ensino Superior completo ou incompleto (Tabela 3) estudadas pelos filhos são Agronomia, Biologia, Ciência da Computação, Contabilidade, Enfermagem, Geografia, Medicina e Teologia.

Tabela 3 - Escolaridade da família

\begin{tabular}{lccc}
\hline Grau de Instrução & Homem & Mulher & Filhos \\
\hline Não Alfabetizado & 1 & 1 & - \\
Primário & 8 & 9 & - \\
Ensino Fundamental & 3 & 2 & - \\
Ensino Fundamental Incompleto & 1 & - & 1 \\
Ensino Médio & 5 & 3 & 9 \\
Ensino Médio Incompleto & - & - & 2 \\
Ensino Superior & 1 & 1 & 3 \\
Ensino Superior Incompleto & - & 2 & 5 \\
Pós-Graduação & - & 1 & - \\
\hline Total & $\mathbf{1 9}$ & $\mathbf{1 9}$ & $\mathbf{2 0}$ \\
\hline
\end{tabular}

Fonte: Dados da pesquisa (2017). 
Realidade divergente pode ser percebida na região de Curvelândia-MT, em que a maioria dos agricultores possui o Ensino Fundamental completo, sem a ocorrência de não alfabetizados (QUEIROZ et al., 2015). Em Nova Xavantina-MT, no Assentamento Banco da Terra, 68\% dos agricultores tinham ensino fundamental (MORAES; SANT'ANA, 2015); resultado semelhante foi encontrado também em São José dos Quatro Marcos-MT (SCHEUER et al., 2016).

O nível educacional está relacionado à capacidade de gestão e facilita o aprendizado e a aplicação de novos conhecimentos na unidade produtiva. Neste sentido, não basta apenas a posse da terra, mas torna-se importante ações sociais para contribuir no processo de capacitação do agricultor (ARAÚJO; BEZERRA, 2010). Para Hage e Almeida (2010), a educação é fundamental para que outras políticas tenham êxito.

Apesar de se localizarem próximas ao perímetro urbano, 94,74\% das famílias residem na propriedade, e mais da metade delas (52,63\%) estão na terra por mais de 21 anos. Em alguns casos já ocorreu a sucessão familiar por meio da transferência da terra como herança. Das famílias, contudo, 31,58\% estão na terra entre 1 e 10 anos, situação que chama atenção, pois, em alguns casos, vêm ocorrendo o processo inverso, em que as famílias do perímetro urbano estão procurando qualidade de vida no contexto rural (Tabela 4).

Tabela 4 - Tempo que a família mora na propriedade

\begin{tabular}{lcc}
\hline Tempo de residência na propriedade & Quantidade & Percentual \% \\
\hline Entre 1 e 10 anos & 6 & 31,58 \\
Entre 11 e 20 anos & 3 & 15,79 \\
Entre 21 e 30 anos & 4 & 21,05 \\
Acima de 31 anos & 6 & 31,58 \\
\hline Total & $\mathbf{1 9}$ & $\mathbf{1 0 0}$ \\
\hline
\end{tabular}

Fonte: Dados da pesquisa (2017).

No que diz respeito à renda oriunda das atividades realizadas na propriedade, $78,94 \%$ das famílias têm obtido renda média de dois a cinco salários mínimos. Já 15,80\% declararam receber acima de seis salários mínimos. Realidade divergente pode ser percebida no estudo de Silva, Simioni e Talamini (2009), em que a maioria das unidades produtivas pesquisadas auferiam renda entre um a dois salários mínimos.

Além da renda da propriedade, $89,47 \%$ das famílias possuem alternativas de renda agrícola e não agrícola, como aposentadorias, arrendamento de parte da propriedade, aluguéis, prestação de serviços (com trator, como pedreiro, carpinteiro, serviços domésticos) e enfermagem; diferente da pesquisa de Gouveia et al. (2012), realizada no assentamento Vale do Sol II no município de Tangará da Serra-MT, em que apenas $25 \%$ das famílias realizavam atividades não agrícolas. O uso de atividades não agrícolas acarreta uma mudança estrutural no meio rural, em que indivíduos da família, com domicílio rural, passam a se dedicar a atividades econômicas e produtivas cada vez menos executadas dentro da propriedade (SCHNEIDER, 2003). 


\section{Perfil das Propriedades}

A lei 11.326/2006 considera agricultor familiar aquele que não possui terra com área maior do que quatro módulos fiscais (BRASIL, 2006). No município de Tangará da Serra-MT, um módulo fiscal equivale a 80 hectares (INCRA, 2013). As propriedades investigadas possuem áreas que variam entre 1,5 a 76 hectares (Tabela 5). Conforme o Censo Agropecuário 2006, a área média dos estabelecimentos familiares no Brasil era de 18,37 hectares; já para o Estado de Mato Grosso a média foi de 56,68 hectares (IBGE, 2006). As áreas de cultivos agrícola e pecuária, todavia, variam entre 0,5 a 10 hectares. A discrepância em algumas propriedades, na área total e trabalhada, deve-se ao fato de alguns agricultores arrendarem parte destas para cultivos de soja, milho e pastagem.

A maioria das famílias opta em diversificar os cultivos (Tabela 5). Segundo um dos agricultores, a prática de diversificar permite que nos momentos de falta de determinado item haja outras alternativas para venda, possibilitando sempre obter renda e não perder o cliente. Neste sentido, Schneider (2010) destaca que sobreviver no contexto rural implica criar estratégias de diversificação de trabalho e renda; desta forma, quanto mais diversificada a unidade produtiva, maiores serão as chances e oportunidades de fazer escolhas.

Tabela 5 - Extensão territorial e atividades das propriedades de Tangará da Serra-MT

\begin{tabular}{|c|c|c|c|}
\hline Agricultor & $\begin{array}{l}\text { Área } \\
\text { Total } \\
\text { (ha) }\end{array}$ & $\begin{array}{c}\text { Área } \\
\text { trabalhada } \\
\text { (ha) }\end{array}$ & Principais tipos de atividades da família \\
\hline 1 & 1,5 & 1 & Quiabo e mandioca \\
\hline 2 & 37 & 10 & Café, mandioca, criação de gado \\
\hline 3 & 76 & 4 & Mamão, banana, tomate e hortaliças \\
\hline 4 & 1 & 0,5 & $\begin{array}{l}\text { Mandioca, milho, abacaxi, cana-de-açúcar, amendoim e } \\
\text { frutíferas }\end{array}$ \\
\hline 5 & 3,5 & 1,5 & Horta, coco, limão, criação de galinha e ovelhas \\
\hline 6 & 7,5 & 7 & $\begin{array}{c}\text { Banana, mamão, batata-doce, abacaxi, manga, limão, } \\
\text { mandioca, abóbora e chuchu }\end{array}$ \\
\hline 7 & 34 & 4 & Milho, criação de gado e galinha \\
\hline 8 & 31 & 10 & Cana-de-açúcar, chuchu e eucalipto \\
\hline 9 & 7 & 4 & Abacaxi, melão, melancia e batata-doce \\
\hline 10 & 28 & 8 & Café, uva, milho, mamão papaia, pitaia e morango \\
\hline 11 & 4 & 3 & Hortaliças, batata-doce, abacaxi, quiabo e mandioca \\
\hline 12 & 24 & 2 & Hortaliças e milho \\
\hline 13 & 15 & 2,5 & Gado leiteiro, milho, maracujá, mamão, jiló e abóbora \\
\hline 14 & 2 & 1 & $\begin{array}{l}\text { Milho, feijão de corda, mandioca, pimenta, abóbora, jiló e } \\
\text { frutíferas }\end{array}$ \\
\hline 15 & 26 & 5 & Milho, gado leiteiro, quiabo e jiló \\
\hline 16 & 10 & 4,5 & $\begin{array}{l}\text { Feijão, limão, maracujá, banana, mandioca, laranja, pi- } \\
\text { menta, galinha e angola }\end{array}$ \\
\hline 17 & 33 & 6 & Hortaliças \\
\hline 18 & 32 & 4 & Milho, mandioca, quiabo, mamão, queijo, gado leiteiro \\
\hline 19 & 25,7 & 5 & Limão, mandioca, acerola e poncã \\
\hline
\end{tabular}

Fonte: Dados da pesquisa (2017). 
Todas as famílias afirmaram ter recebido assistência e orientação técnica de diversas instituições, como Empaer, Unemat, Serviço Brasileiro de Apoio às Micro e Pequenas Empresas de Mato Grosso (Sebrae), prefeituras e, em alguns casos, serviços particulares. A maioria, contudo, afirma que a assistência ocorre de forma esporádica. Percebe-se que a realidade identificada neste estudo foge à regra geral; assim, o fato de as propriedades pesquisadas estarem localizadas próximas ao perímetro urbano, pode ter contribuído para este resultado. Situação divergente foi constatada por Ruiz (2016) em Tangará da Serra-MT, por Lemes e Bresciane (2010) em Juína-MT e por Moraes e Sant'Ana (2015) em Nova Xavantina-MT, em que a falta de assistência foi relatada por todos agricultores.

Para manutenção dos afazeres da propriedade e irrigação dos cultivos, $84,21 \%$ captam água de córregos e $15,79 \%$ de poços artesianos. Os sistemas de irrigação utilizados são: aspersão, microaspersão e gotejamento. Quanto à análise de solo, 94,74\% destacaram já ter realizado. No que diz respeito ao uso de alguma política pública, 63,16\% das famílias conseguiram recursos do Pronaf e $31,58 \%$ já participaram do Programa Nacional de Alimentação Escolar (PNAE). Infere-se, portanto, que o fato de ter assistência técnica pode ser o diferencial para que estes agricultores tenham acesso às políticas públicas.

Em Cruz Alta-RS os agricultores destacaram a falta de auxílio técnico como entrave na aquisição do Pronaf, por ser um processo burocrático que envolve muitos documentos, pois $95,07 \%$ são informados sobre os períodos e modalidades por meio dos bancos, enquanto 4,93\% pela Empresa Estadual de Assistência Técnica e Extensão Rural (Emater) (MERA; DIDONET, 2010).

Conforme destacado por Santos et al. (2012), as políticas públicas de fomento têm papel fundamental para esta parcela da sociedade, pois contribuem para ampliar o potencial produtivo dos agricultores, bem como possibilita a permanência das famílias no campo e a continuidade da produção.

\section{Interesse em Diversificar a Propriedade com o Cultivo de Flores}

Em relação aos planos de novos cultivos na propriedade, 63,16\% dos agricultores responderam não possuir, alegando idade avançada, pouca mão de obra e estarem satisfeitos com os resultados obtidos. Um dos entrevistados - filho que recentemente assumiu a propriedade após o falecimento do pai -, porém, declarou que, por ele, venderia tudo e voltaria à cidade para ter uma renda fixa, justificando que no campo há épocas que não há renda e que só retornou para não deixar a mãe sozinha. Stuani, Neckel e Ficagna (2016) destacam que na agricultura familiar o processo sucessório somente ocorre após o falecimento ou incapacidade dos pais, sendo esta quase uma regra. Nesse sentido, percebe-se a necessidade de fomentar alternativas de rendas mediante a diversificação, para que este filho melhore sua percepção de vida no campo.

Dos agricultores que afirmaram ter interesse em investir em novos cultivos ou expandir os já realizados, $36,84 \%$ destacaram atividades como plantio de frutíferas (bananeira, cupuaçu, poncã, rambutam, morango), pastagens, criação de gado, tanques de peixe e leguminosas. Um dos entrevistados enfatizou não ver outro caminho a não ser diversificar diante da saturação dos cultivos já realizados e exigências dos clientes conquistados. 
Embora apenas 36,84\% dos agricultores afirmaram ter interesse de investir em novos cultivos ou expandir aqueles realizados na propriedade, nota-se mudança após os questionamentos e apresentação da oportunidade com a floricultura tropical. O principal motivo percebido, gerador dessa mudança de opinião, é o desconhecimento de novas alternativas ou potencialidades a serem exploradas de acordo com as características do Estado.

Inicialmente questionados se conheciam alguma espécie de flor tropical, os agricultores responderam que não, porém quando apresentadas algumas imagens de flores tropicais, como alpínia e helicônia, 94,74\% disseram conhecer denominando as como banana de macaco, kaité, entre outras. Conforme destacado por França et al. (2010), o pouco conhecimento das flores tropicais pela população em geral impacta na sua desvalorização no mercado. Assim, percebe-se a predominância do conhecimento tradicional em relação ao científico, uma vez que, popularmente, as espécies de flores tropicais são conhecidas pela maioria dos agricultores.

Segundo Dickmann e Dickmann (2008), o saber popular deve ser valorizado, pois consiste nos conhecimentos transmitidos baseados na experiência pessoal de geração em geração, que nem sempre está descrito em livros. Neste sentido, a falta de diálogo entre a linguagem científica, criada pela ciência, e a linguagem da vida cotidiana, baseada na prática e nos contextos sociais, acabam impactando no avanço da ciência, quando não caminham juntas.

A maioria das famílias $(73,68 \%)$ afirmou já ter visto espécies nativas na propriedade, principalmente nas bordas das matas e margens dos córregos (Tabela 6). Tal afirmação também foi constatada por Almeida et al. (2012), os quais identificaram que a maioria das espécies tropicais são típicas de regiões com as características descritas pelos agricultores. Apesar de conhecer as espécies, contudo, mais da metade das famílias $(57,89 \%)$ nunca ouviu falar sobre a possibilidade de cultivo comercial. Dentre aqueles que afirmaram conhecer, alegaram que foi por intermédio da Unemat, Globo Rural, reportagens sobre produções ocorridas nos municípios de Várzea Grande-MT, Cuiabá-MT, e por meio de feiras em Estados do Sul.

Quando indagados se acreditam na floricultura tropical como uma alternativa viável, 78,95\% afirmaram que sim (Tabela 6).

Tabela 6 - Conhecimento e interesse na produção de flores tropicais

\begin{tabular}{|l|l|c|c|c|c|}
\hline \multirow{2}{*}{$\mathbf{N}^{\circ}$} & \multicolumn{1}{|c|}{ Questão } & \multicolumn{2}{c|}{ Sim } & \multicolumn{2}{c|}{ Não } \\
\cline { 3 - 6 } & Quant. & $\%$ & Quant. & $\%$ \\
\hline 12 & Tem conhecimento de alguma espécie de flor tropical? & 18 & 94,74 & 1 & 5,26 \\
\hline 13 & Já viu espécies de flores tropicais na propriedade? & 14 & 73,68 & 5 & 26,32 \\
\hline 14 & Já ouviu falar sobre cultivo comercial de flores tropicais? & 8 & 42,11 & 11 & 57,89 \\
\hline 15 & $\begin{array}{l}\text { Acredita que o cultivo de flores tropicais pode ser uma } \\
\text { alternativa de diversificação viável? }\end{array}$ & 15 & 78,95 & 4 & 21,05 \\
\hline 16 & $\begin{array}{l}\text { Teria interesse em produzir flores tropicais como alter- } \\
\text { nativa de diversificação da renda? }\end{array}$ & 10 & 52,63 & 9 & 47,37 \\
\hline
\end{tabular}

Fonte: Dados da pesquisa (2017). 
O Quadro 2 demonstra algumas justificativas dos motivos que levam estes agricultores a acreditarem na viabilidade da produção de flores tropicais.

Quadro 2 - Motivos que levam os entrevistados a acreditar que a floricultura tropical seja viável como alternativa de diversificação

\begin{tabular}{|c|l|}
\hline Entrevistados & Descrição \\
\hline 5 & $\begin{array}{l}\text { Acreditam que trabalhar com flores tropicais seria uma opção viável e que } \\
\text { trabalhariam menos se comparada à horticultura, uma vez que o casal } \\
\text { encontra-se em idade avançada, todavia, há dúvida: A horta sempre tem } \\
\text { onde comercializar e as flores? }\end{array}$ \\
\hline 10 & $\begin{array}{l}\text { Declararam que precisam conhecer mais, em termos de cultivo, investi- } \\
\text { mentos, como se comportaria o mercado e não sabem se o clima e a terra } \\
\text { da região ajudariam. }\end{array}$ \\
\hline 12 & $\begin{array}{l}\text { Alegaram que daria certo sim, pelo fato de flores ser um tipo de cultivo } \\
\text { que as pessoas valorizam e têm grande mercado, pouco explorado, contu- } \\
\text { do; então necessitariam de apoio técnico e contatos comerciais. }\end{array}$ \\
\hline 15 & $\begin{array}{l}\text { Destacaram que, por ser um nicho novo na região e Mato Grosso quase } \\
\text { não possuir produtores, seria viável, uma vez que a cidade de Tangará da } \\
\text { Serra-MT cresceu nos últimos anos e têm muitos eventos. }\end{array}$ \\
\hline
\end{tabular}

Fonte: Dados da pesquisa (2017).

Dentre os entrevistados que não acreditam que a atividade seria viável, as alegações foram: venderiam pouco e, dependendo da forma de comercialização, causaria muitos transtornos; por achar que as flores são mais bonitas na natureza; pelo fato de o município de Tangará da Serra-MT não possuir a cultura de produção e comercialização dessas espécies; e por não conhecer o manejo de cultivo.

Infere-se que a floricultura tropical, se trabalhada como uma alternativa de diversificação, com produção em pequena escala ou por meio da formação de cooperativas, possibilitaria um complemento de renda para muitas famílias, podendo elas realizar parcerias públicas e privadas para abastecer vários eventos, bem como o serviço de assinatura floral, prática já realizada no Estado, em que toda semana o agricultor coloca um arranjo diferente em diversos ambientes, como escritórios, consultórios, restaurantes, etc.

O Quadro 3 evidencia algumas das razões pelo interesse em diversificar com o cultivo de flores tropicais.

Quadro 3 - Justificativas do interesse em diversificar com o cultivo de flores tropicais

\begin{tabular}{|c|l|}
\hline Entrevistados & Descrição \\
\hline 8 & $\begin{array}{l}\text { O fato de essas flores serem da região faz com que não precise muito de } \\
\text { veneno e mão de obra. }\end{array}$ \\
\hline 10 & $\begin{array}{l}\text { Teria interesse, entretanto acreditam que mão de obra seria o problema, e } \\
\text { que plantar é fácil, mas precisa de acompanhamento técnico. O produtor } \\
\text { quer saber como é e para quem comercializar. Eis a questão-chave. }\end{array}$ \\
\hline 7 & $\begin{array}{l}\text { Uma boa ideia que deve ser estudada por ser nova. Quem, porém, seria o } \\
\text { público consumidor? É uma ideia que não temos na nossa cabeça. }\end{array}$ \\
\hline 15 & $\begin{array}{l}\text { É bom. Seria mais uma fonte de renda na propriedade. Se tiver suporte e } \\
\text { assistência daria para experimentar. Quanto, porém, ficaria o investimen- } \\
\text { to? E qual seria o valor para venda? }\end{array}$ \\
\hline
\end{tabular}


Os resultados obtidos demonstram que os agricultores possuem interesse, todavia existem muitas dúvidas com relação aos tratos culturais, investimento e o mercado de flores tropicais, por ser ainda pouco explorado no Estado de Mato Grosso. O estudo de Santos et al. (2017), no Estado de Mato Grosso, considerou a produção de flores tropicais rentável, com retorno do investimento total relativamente curto, variando de 2,33 a 3,08 anos. Na visão do produtor, por ser um nicho com maior demanda que oferta no Estado, tem gerado retorno econômico rápido.

Na pesquisa realizada no Estado do Rio de Janeiro a produção das espécies tropicais alpínia, bastão do imperador e antúrio, apresentou ter sido uma alternativa de renda promissora para agricultores, proporcionando resultados econômicos positivos, tendo em vista que as culturas alternativas podem ser um diferencial de êxito no empreendimento rural (MACHADO NETO; JASMIM; PONCIANO (2013). Dificuldades, contudo, podem ser encontradas, como na região de Porto Velho-RO, onde a falta de canais de comercialização da floricultura tropical tem resultado em um nível elevado de perdas (FRANÇA et al., 2010), necessitando, portanto, de políticas públicas que deem maior visibilidade para a atividade.

\section{CONSIDERAÇÕES FINAIS}

Os resultados permitiram constatar que a maioria das famílias conhece as flores tropicais, porém por meio de nomes populares, e já visualizou espécies nativas na propriedade. Desconhecia, no entanto, a possibilidade de cultivo para comercialização, mas acredita no potencial das flores tropicais como alternativa viável de produção. Infere-se que, apesar de a maioria dos entrevistados possuir interesse no cultivo para comercialização como estratégia de diversificação de renda, existem muitas dúvidas em relação às formas de cultivo, investimento e comercialização, por ser uma atividade pouco explorada e conhecida por eles no Estado.

Neste sentido, a floricultura tropical pode ser uma alternativa de diversificação de cultivo e renda, mas também um desafio para os agricultores se não houver parcerias público-privadas para subsidiá-los em questões técnicas, capital social necessário para investimento, criação de linhas de crédito para o segmento, incentivo e estruturação de canais de comercialização para escoamento da produção no contexto social da região.

Diante do interesse e das dúvidas dos agricultores, sugere-se novas pesquisas no âmbito da floricultura tropical, a fim de traçar o panorama da cadeia de comercialização e perfil dos consumidores nas condições do Estado de Mato Grosso. Tais dados, se disseminados pela publicação científica e por dias de campo como aqueles já realizados pela Universidade do Estado de Mato Grosso, em Tangará da Serra-MT, poderão servir de base para os produtores que queiram investir, pois este é um campo que carece de pesquisas envolvendo as mais diversas áreas do conhecimento e elaboração de políticas públicas de fomento à assistência técnica especializada na floricultura tropical para o Estado. 


\section{REFERÊNCIAS}

AKI, A.; PEROSA, J. M. Y. Aspectos da produção e consumo de flores e plantas ornamentais no Brasil. Revista Brasileira de Horticultura Ornamental, Campinas, v. 8, n. 1/2, p. 13-23, 2002.

ALMEIDA, E. F. A. et al. Flores tropicais em Minas Gerais. Circular Técnica, n. 176, p. 1-5, nov. 2012.

ARAÚJO, G. F.; BEZERRA, C. As potencialidades socioeducativas dos assentamentos da reforma agrária. In: CONGRESSO LATINOAMERICANO DE SOCIOLOGIA RURAL, 2010, Porto de Galinhas. Anais eletrônicos [...]. Porto de Galinhas, 2010.

ARRUDA, C. A. S. de; VILANOVA, S. R. F.; CHICHORRO, J. F. Turismo rural e agricultura familiar: o caso de Nossa Senhora do Livramento-MT. Interações, Campo Grande, v. 9, n. 2, p. 149-157, jul./dez. 2008.

ATLAS DO DESENVOLVIMENTO HUMANO NO BRASIL. Perfil do município de Tangará da Serra /MT. 2013. Disponível em: http://atlasbrasil.org.br/2013/pt/perfil_m/tangara-da-serra_mt. Acesso em: 7 jun. 2017.

BERQUO, E.; CAVENAGHI, S. Fecundidade em declínio: breve nota sobre a redução no número médio de filhos por mulher no Brasil. Novos Estud. Cebrap, São Paulo, n. 74, p. 11-15, mar. 2006.

BEZERRA, G. J.; SCHILINDWEIN, M. M. Agricultura familiar como geração de renda e desenvolvimento local: uma análise para Dourados, MS, Brasil. Interações, Campo Grande, MS, v. 18, n. 1, p. 3-15, jan./mar. 2017.

BRASIL. Lei no 11.326, de 24 de julho de 2006. Diário Oficial [da] República Federativa do Brasil, Poder Legislativo, Brasília, DF, 25 jul. 2006. Seção 1, p. 1.

CAREgNATO, R. C. A.; MUTTI, R. Pesquisa qualitativa: análise de discurso versus análise de conteúdo. Texto \& Contexto Enfermagem, Florianópolis, v. 15, n. 4, p. 679-84, out./dez. 2006.

CAVALHEIRO, C. N. et al. Perfil socioeconômico e análise da qualidade de vida dos produtores de leite da comunidade São Justino, em Juína-MT. Revista Destaques Acadêmicos, v. 6, n. 3, 2014.

CINTRA, A. P. de U.; BAZOTTI, A. População rural, agricultura familiar e transmissão do saber na região Sul. Caderno Ipardes Estudos e Pesquisas, Curitiba, v. 2, n. 1, p. 80-94, jan./jun. 2012.

DEGGERONE, Z. A. A permanência dos jovens nas unidades de produção familiares na Região Alto Uruguaia, Rio Grande do Sul. 2014. Dissertação (Mestrado em Ambiente e Desenvolvimento) - Univates, Lajeado, 2014.

DICKMANN, I.; DICKMANN, I. Primeiras palavras de Paulo Freire. Passo Fundo, Battistel, 2008.

DUVAL, C. M. A produção de flores e a agricultura familiar. Revista Horticultura Brasileira, Brasília, DF, v. 32, n. 2, abr./jun., 2014.

FAO. Organização das Nações Unidas para a Alimentação e Agricultura. Colocar os agricultores familiares em primeiro para erradicar a fome. 2014. Disponível em: https://www.fao.org.br/cafppef.asp. Acesso em: 3 jun. 2019.

FARIA, R. B. et al. Recursos genéticos vegetais comercializados na feira do produtor de Tangará da Serra-MT. Biodiversidade, v. 15, n. 3, 2016.

FRANÇA, C. A. M. et al. Flores e folhagens tropicais: mercado em expansão. In: ENCONTRO NACIONAL DA ANPPAS, 5., 2010, Florianópolis-SC. Anais [...]. Florianópolis-SC, 2010.

GAZOLLA, M.; SCHNEIDER, S. A produção da autonomia: os "papéis" do autoconsumo na reprodução social dos agricultores familiares. Estudos Sociedade e Agricultura, Rio de Janeiro, v. 15, n. 1, p. 89-122, 2007.

GEHLEN, I. Políticas públicas e desenvolvimento social rural. Revista São Paulo em Perspectiva, São Paulo, v. 18, n. 2, p. 95-103, 2004.

GODOY, C. M. T. et al. Juventude rural, envelhecimento e o papel da aposentadoria no meio rural: a realidade do município de Santa Rosa/RS. In: SOCIEDADE BRASILEIRA DE ECONOMIA, ADMINISTRAÇÃO E SOCIOLOGIA RURAL - SOBER, 2010, Campo Grande. Anais [...]. Campo Grande, MS, 2010.

GOUVEIA, R. G. L. de et al. Diagnóstico sobre a administração de famílias assentadas de Tangará da Serra-MT: o caso do projeto de crédito fundiário Vale do Sol II. Revista Brasileira Agrociência, Pelotas, v. 18, n. 4, p. 283-291, 2012.

HAGE, S. A. M.; ALMEIDA, L. S. Desafios da educação nos assentamentos da reforma agrária da amazônia paraense. In: CONGRESSO LATINOAMERICANO DE SOCIOLOGIA RURAL, 2010, Porto de Galinhas. Anais eletrônicos [...]. Porto de Galinhas, 2010.

HAIR JUNIOR, J.F. et al. Análise multivariada de dados. 5. ed. Porto Alegre: Bookman, 2005.

HAUBRICHT, D. M.; FIORINI, F. A. Percepção ambiental dos moradores do assentamento Vila Rural I do município de Alta Floresta - MT. Revista da Universidade Vale do Rio Verde, Três Corações, v. 12, n. 1, p. 248-256, jan./jul. 2014. 
IBGE. Instituto Brasileiro de Geografia e Estatística. Censo Agropecuário 2006. Agricultura familiar primeiros resultados. Disponível em: http://biblioteca.ibge.gov.br/visualizacao/periodicos/50/agro_2006_agricultura_familiar.pdf. Acesso em: 22 jul. 2017.

IBGE. Instituto Brasileiro de Geografia e Estatística. Indicadores IBGE. Estatística de produção agrícola janeiro de 2017. 2017. Disponível em: ftp://ftp.ibge.gov.br/Producao_Agricola/Fasciculo_Indicadores_ IBGE/estProdAgr_201701.pdf. Acesso em: 10 jul. 2017.

IBGE. Instituto Brasileiro de Geografia e Estatística. Cidades. 2018. Disponível em: https://cidades.ibge. gov.br/brasil/mt/tangara-da-serra/panorama Acesso em: 3 jun. 2019.

INCRA. Instituto Nacional de Colonização de Reforma Agrária. Sistema Nacional de Cadastro Rural - índices básicos de 2013. 2013. Disponível em: http://www.incra.gov.br/sites/default/files/uploads/estrutura-fundiaria/regularizacao-fundiaria/indices-cadastrais/indices_basicos_2013_por_municipio.pdf. Acesso em: 20 jul. 2017.

JUNQUEIRA, A. H.; PEETZ, M. da S. Mercado interno para os produtos da floricultura brasileira: características, tendências e importância socioeconômica recente. Revista Brasileira de Horticultura Ornamental, Brasília-DF, v. 14, n. 1, p. 37-52, 2008.

LAMAS, A. M. Floricultura tropical: tecnologia de produção. Tabatinga, AM: Sebrae, 2004. 65p.

LANGE, A. K.; AREND, S. C. Plantas ornamentais para paisagismo: estudo de caso em municípios do Rio Grande do Sul - Brasil. Informe Gepec, Toledo, v. 16, n. 2, p. 115-130, jul./dez. 2012.

LEMES, D. P.; BRESCIANI, D. G. A agricultura familiar no município de Juína: uma análise de caso dos produtores da Aprofeju. Revista Científica da Ajes, Juína, v. 1, n. 2, p. 1-15, set./dez. 2010.

LIMA, A. de F. A.; ZOMER, C. Condições gerais da organização e da produção em assentamento rural de Aripuanã-MT e o acesso dos produtores aos incentivos e benefícios federais. In: CONGRESSO VIRTUAL BRASILEIRO DE ADMINISTRAÇÃO - CONVIBRA, 8., 2011, São Paulo. Anais [...]. São Paulo, 2011.

LOGES, V. et al. Colheita, pós-colheita e embalagem de flores tropicais em Pernambuco. Horticultura Brasileira, Brasília, v. 23, n. 3, p. 699-702, jul./set. 2005.

LOMACHINSKY, M. H. A evolução da floricultura pernambucana: um novo produto na pauta de exportações do Estado. 2005, 75f. Dissertação (Mestrado em economia) - Universidade Federal de Pernambuco, Recife, 2005.

MACHADO NETO, A. S.; JASMIM, J. M.; PONCIANO, N. J. Indicadores econômicos da produção de flores tropicais no Estado do Rio de Janeiro. Rev. Ceres, Viçosa, v. 60, n. 2, p. 173-184, mar/abr. 2013.

MALHOTRA, N. K. et al. Introdução à pesquisa de marketing. São Paulo: Editora Pearson Prentice Hall, 2005.

MDA. Ministério de Desenvolvimento Agrário. Plano de safra da agricultura familiar 2017/2020. Fortalecer o campo para desenvolver o Brasil. 2017. Disponível em: http://www.mda.gov.br/sitemda/plano-safra-da-agricultura-familiar-20172020. Acesso em: 11 jul. 2017.

MERA, C. P.; DIDONET, G. B. Aplicação dos recursos do Pronaf pelos agricultores familiares do município de Cruz Alta - RS. Perspectiva Econômica, v. 6, n. 2, p. 45-58, jul./dez. 2010.

MORAES, M. D. de; SANT'ANA, A. L. Características socioeconômicas do Assentamento Banco da Terra, Nova Xavantina (MT): uma análise sob a ótica da adoção ou construção de conhecimentos. RESR, Piracicaba, SP, v. 53, n. 4, p. 589-606, out./dez. 2015.

MORENO, G. Políticas e estratégias de ocupação. In: MORENO, G.; HIGA, T. C. S. Geografia de Mato Grosso: território, sociedade, ambiente. Cuiabá: Entrelinhas, 2005. p. 34-51.

NASCIMENTO, L. J. Em alta, mercado de flores tropicais vira aposta na terra do agronegócio. 2014. Disponível em: http://g1.globo.com/mato-grosso/agrodebate/noticia/2014/12/em-alta-mercado-de-flores-tropicais-vira-aposta-na-terra-do-agronegocio.html. Acesso em: 6 jun. 2017.

OLIVEIRA, C. E. de. Famílias e natureza: as relações entre famílias e ambiente na colonização de Tangará da Serra-MT. 2003, 229f. Dissertação (Mestrado em História) - Universidade Federal de Mato Grosso, Cuiabá, MT, 2003.

OLIVEIRA, C. E. de. Migração e escolarização: história de instituições escolares de Tangará da Serra Mato Grosso - Brasil 1964-1976. 2009, 335f. Tese (Doutorado em Educação) - Universidade Federal de Uberlândia, Uberlândia, MG, 2009.

PERSONA, R. Flores tropicais podem ser alternativa para pequenos produtores. 2016. Disponível em: http://www.mt.gov.br/-/2938964-flores-tropicais-podem-ser-alternativa-para-pequenos-produtores. Acesso em: 10 jul. 2017.

QUEIROZ, R. F. N. de et al. Agricultura familiar no município de Curvelândia-MT: análise da produção vinculada ao Programa de Aquisição de Alimentos (PAA). Bol. Geogr., Maringá, v. 33, n. 3, p. 184-200, set./ dez. 2015. 
RICHARDSON, R. J. et al. Pesquisa social, métodos e técnicas. 3. ed. rev. ampliada. São Paulo, Atlas, 2012. RUIZ, C. G. L. Atualidades, desafios e perspectivas para o controle da traça-das-crucíferas na agricultura familiar. 2016, 43f. Dissertação (Mestrado em Ambiente e Sistemas de Produção Agrícola) - Universidade do Estado de Mato Grosso, Tangará da Serra, 2016.

SANTOS, A. R. dos et al. Agricultura familiar e segurança alimentar e nutricional: análise dos resultados do Programa de Aquisição de Alimentos (PAA Doação simultânea) nos Estados da Bahia e Minas Gerais. Cadernos de Gestão Social, v. 3, n. 1, jan./jun. 2012.

SANTOS, J. S. C. et al. Produção de flores tropicais: uma análise econômica na agricultura familiar em Mato Grosso. In: CONGRESSO BRASILEIRO DE CUSTOS, 24., 2017, Florianópolis. Anais [...]. Florianópolis, 2017.

SANTOS, N. dos. Flores tropicais que encantam e fortalecem agricultura familiar, 2015. Disponível em: http://www3.mt.gov.br/sala-de-imprensa/radio-paiaguas/flores-tropicais-que-encantam-e-fortalecem-agricultura-familiar/148927. Acesso em: 10 jul. 2017.

SCHEUER, J. M. et al. Aspectos socioeconômicos dos agricultores familiares da Associação dos Pequenos Produtores da Região do Alto Sant'Ana, Mato Grosso. Revista Brasileira de Gestão e Desenvolvimento Regional, Taubaté, v. 12, n. 1, p. 85-106, jan./abr. 2016.

SCHNEIDER, S. A pluriatividade na agricultura familiar. Porto Alegre: Editora da UFRGS, 2003. (Coleção Estudos Rurais).

SCHNEIDER, S. Reflexões sobre diversidade e diversificação. Ruris - Revista do Centro de Estudos Rurais, Campinas-SP, v. 4, n. 1, p. 85-131, mar. 2010.

SCHWAAB, A. Tangará: Associação da Feria do Produtor tem novo presidente. 2017. Disponível em: http://www.radiopioneira.com.br/noticia/40884/tangara\%3A-associacao-da-feira-do-produtor-tem-novo-presidente-. Acesso em: 10 jul. 2017.

SEBRAE. Serviço Brasileiro de Apoio às Micro e Pequenas Empresas de Mato Grosso. Negócio desabrocha com conhecimento. 2016. Disponível em: https://www.mt.sebrae.com.br/conteudo-digital/135. Acesso em: 10 jul. 2017.

SEPLAN. Secretaria de Estado de Planejamento e Coordenação Geral. Anuário Estatístico de Mato Grosso. 2015. Ano base 2013. Cuiabá.

SETUR. Secretaria de Turismo de Tangará da Serra-MT. Economia de Tangará. 2015. Disponível em: http:// www.tangaradaserra.mt.gov.br/turismo/Economia/. Acesso em: 10 jul. 2017.

SILVA, C. da.; SIMIONI, F. J.; TALAMINI, E. Fatores determinantes da renda de famílias rurais no município de Painel - SC. Teoria e evidência econômica, n. 32, p. 35-54, jan./jun. 2009.

SILVA, J. F. G. da. Quem precisa de uma estratégia de desenvolvimento? Textos para Discussão Nead, Campinas, v. 2, n. p. 5-52, 2001.

SILVA, J. R.; JESUS, P. Os desafios do novo rural e as perspectivas da agricultura familiar no Brasil. In: CONGRESSO NORTE E NORDESTE DE PESQUISA E INOVAÇÃO - CONNEPI, 5., 2010, Maceió. Anais [...]. Maceió, 2010. Disponível em: http://connepi.ifal.edu.br/ocs/anais/. Acesso em: 3 jun. 2019.

SIMÃO, A. A. Diversificação como alternativa para o desenvolvimento da agropecuária familiar Sul Mineira. 2004, 160f. Dissertação (Mestrado em Administração) - Universidade Federal de Lavras, Minas Gerais, 2005.

SPANEVELLO, R. M. et al. As perspectivas sucessórias de gestão dos negócios do patrimônio entre agricultores familiares sem sucessores. Revista CCEI, v. 14, n. 26, ago. 2010.

STUANI, C.; NECKEL, A.; FICAGNA, A. V. O. Jovens herdeiros: uma análise da sucessão familiar em pequenas propriedades rurais de Nova Araçá. In: ENCONTRO DE ESTUDOS SOBRE EMPREENDEDORISMO E GESTÃO DE PEQUENAS EMPRESAS - EGEPE, 9., 2016, Passo Fundo. Anais [...]. Passo Fundo, RS, 2016.

TERRA, S. B.; ZUGE, D. P. P. de O. Floricultura: a produção de flores como uma nova alternativa de emprego e renda para comunidade de Bagé-RS. Revista Conexão, Ponta Grossa, v. 9, n. 2, jul./dez. 2013.

TUMELERO, D. M.; MATTOS, J. L. S. de. Diagnóstico sócio, econômico, ambiental e potencial para a agricultura orgânica no município de Sorriso-MT. Revista de Ciências Agro-Ambientais, Alta Floresta, v. 4, n. 1, p. 1-14, 2006.

UNEMOTO, L. K. Cultivo de bastão do imperador [Etlingera elatior (Jack) R. M. Smith] em diferentes espaçamentos no Norte do Paraná. Londrina, 2010, 70f. Tese (Doutorado em Agronomia) - Universidade Estadual de Londrina, Centro de Ciências Agrárias, Programa de Pós-Graduação em Agronomia, 2010. 